\title{
O CANTO COLETIVO NAS ESCOLAS DO PIBID DE MÚSICA
}

\author{
Larissa de Carvalho Goncalves ${ }^{1}$; Simone Marques Braga²; \\ 1. Bolsista PIBIC/FAPESB, Graduando em Licenciatura em Música, Universidade Estadual de Feira de Santana, \\ e-mail: larycarvalhog@live.com \\ 2. Orientadora, Departamento de Letras e Artes, Universidade Estadual de Feira de Santana, \\ e-mail: moninhabraga@gmail.com
}

PALAVRAS-CHAVE: Aula de Música; Canto Coletivo; PIBID.

\section{INTRODUÇÃO}

O presente trabalho, que contou com o apoio da Fundação de Amparo a Pesquisa do Estado da Bahia (FAPESB), tem como proposta apresentar uma pesquisa que buscou investigar a abordagem do canto coletivo ${ }^{1}$ junto às práticas pedagógicas desenvolvidas pelos ex-bolsistas do Subprojeto Musicando a Escola, na atuação em cinco escolas públicas de Feira de Santana, parceiras do Programa Institucional de Bolsa de Iniciação à Docência (PIBID) ${ }^{2}$, vinculado ao curso de Licenciatura em Música da Universidade Estadual de Feira de Santana (UEFS). A escolha por esta temática se deve ao fato da minha participação no programa como bolsista e ter vivenciado poucas praticas pedagógicas com o canto. Assim, a problematização desta pesquisa é verificar como foi trabalhado o canto coletivo nas escolas, a partir da questão problema: de que forma acontecem as atividades pedagógicas musicais do canto coletivo no PIBID de Música da UEFS?, por isso, o objetivo principal foi investigar as formas em que foram contempladas atividades que envolveram o canto coletivo. Como objetivos específicos buscaram-se identificar os recursos disponíveis para as aulas; conhecer o repertório utilizado; conhecer e descrever as atividades práticas de canto coletivo; verificar as dificuldades, desafios e habilidades docentes necessárias para desenvolver a prática do canto em sala.

\section{METODOLOGIA}

Nesta pesquisa de caráter qualitativo, foram investigados como ocorrem e quais os desafios das práticas do canto coletivo nas escolas que foram parceiras do PIBID de Música da UEFS, a saber: Instituto de Educação Gastão Guimarães (Ensino Fundamental II e Ensino Médio), Centro Integrado de Educação Municipal Professor Joselito Amorim (Ensino Fundamental I e II), Centro Integrado de Educação Assis Chateaubriand (Ensino Fundamental II e Ensino Médio), Colégio Modelo Luís Eduardo Magalhães (Ensino Médio), Colégio Estadual Teotônio Vilela (Ensino Fundamental II e Ensino Médio), incluindo apenas informações coletadas junto aos ex-bolsistas. Assim, primeiro foi realizada uma enquete virtual para cada uma das escolas investigadas, as

\footnotetext{
${ }^{1}$ Sobre o termo "canto coletivo" trata-se de uma nomenclatura recente utilizada para a atividade de cantar em conjunto (FUCCI AMATO, 2007).

2 Apesar de haver mobilizações, em fevereiro de 2018, a Coordenação de Aperfeiçoamento de Pessoal de Nível Superior (CAPES) decidiu não dar continuidade ao edital $n^{\circ}$ 61/2013 (2014-2018). Consequentemente, as bolsas concedidas, referentes a este edital foram canceladas, por conta disso, o termo utilizado nesse trabalho para os participantes entrevistados será "ex-bolsistas".
} 
quais possuem subgrupos no Facebook, que é utilizado para comunicação e compartilhamento de experiências, atividades e planejamentos desenvolvidos na escola. Nesses subgrupos os participantes foram divididos por escolas. Desta forma, para cada grupo esta enquete contemplou a seguinte questão: Você trabalha o canto com os estudantes em sala de aula?, podendo o ex-bolsista responder sim ou não. Assim, se chegou ao total de 10 ex-bolsistas selecionados, entretanto, apenas 8 se disponibilizaram a participar da segunda etapa que foi a entrevista.

O roteiro da entrevista foi estruturado com 07 perguntas abertas, sendo estas: 1. Qual a sua aproximação com a atividade do canto coletivo? 2. Quais os desafios que você se deparou em sala de aula para desenvolver a prática do canto? 3. Quais os recursos disponíveis para as aulas? 4. Qual o repertório utilizado? 5. Descreva como acontece ou aconteceu à prática do canto nas suas turmas. 6. Quais habilidades docentes você precisou desenvolver para a realização desta prática? 7. Quais habilidades docentes você considera necessárias para a utilização do canto?

O instrumento foi disponibilizado por meio do WhatsApp, a fim de favorecer a disponibilidade de cada bolsista, pois alguns residiam em outras cidades. As respostas foram registradas por meio da gravação de áudio, com duração aproximada de 20 minutos. O primeiro passo para o tratamento dos dados foi organizar as informações por escola, e posteriormente foram transcritas as entrevistas para otimização de tempo e favorecimento da análise.

\section{ANÁLISE}

Sobre a atividade do canto coletivo, os ex-bolsistas possuem atividades muito próximas do canto $\operatorname{coral}^{3}$, como a prática de aquecimentos e exercícios técnicos, seguido do ensaio, ou pela integração com outras artes, como o teatro e a apresentação ao público (possivelmente pelos estudantes terem cursado a disciplina Canto Coral). Houve um avanço no desenvolvimento do uso do canto nas atividades (comparado a minha época de bolsista). Das 5 escolas, $50 \%$ dos ex-bolsistas entrevistados possuíam aproximação com o canto coletivo, conforme a figura 1 abaixo.

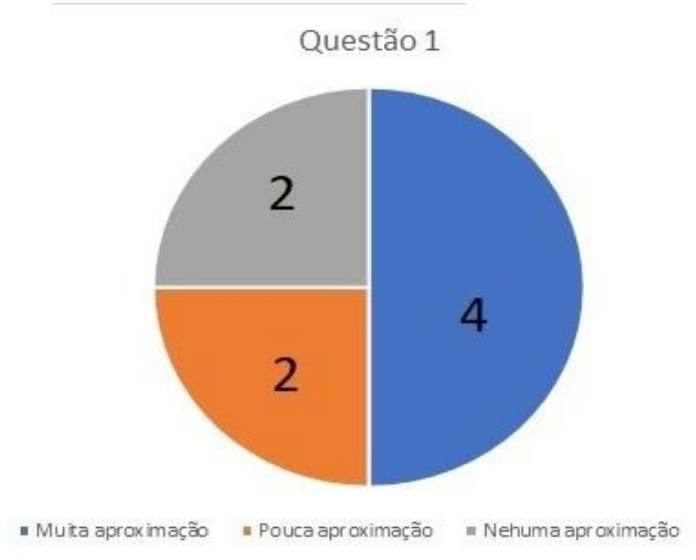

Figura 1: Aproximação com o canto coletivo

\footnotetext{
${ }^{3}$ Até 1832 , os grupos de canto coletivo eram nomeados pela terminologia coral. No entanto, o canto coral existe algumas peculiaridades características da atividade, como: a prática dos aquecimentos vocais e corporais, ensaio do repertório com divisões de linhas melódicas diferentes, estando de acordo com a classificação vocal de cada um.
} 
Não foi visto uma modificação significante em relação aos recursos e materiais didáticos do período ao qual participei do programa. Ao notar alguns trabalhos desenvolvidos por alguns ex-bolsistas, percebe-se que o desafio não é tanto por não ter um instrumento harmônico ${ }^{4}$ para auxiliar nas atividades desenvolvidas, mas sim uma questão da formação pedagógica do indivíduo, de ter o domínio de conhecimentos e habilidades, a exemplo de trabalhar somente com a voz, sem auxílio de instrumento harmônico. Ainda sobre instrumentos, poucos ex-bolsistas utilizavam a percussão corporal, já que o corpo é um instrumento próprio de cada um (Schimiti, 2003), conforme é indicado na figura 2.

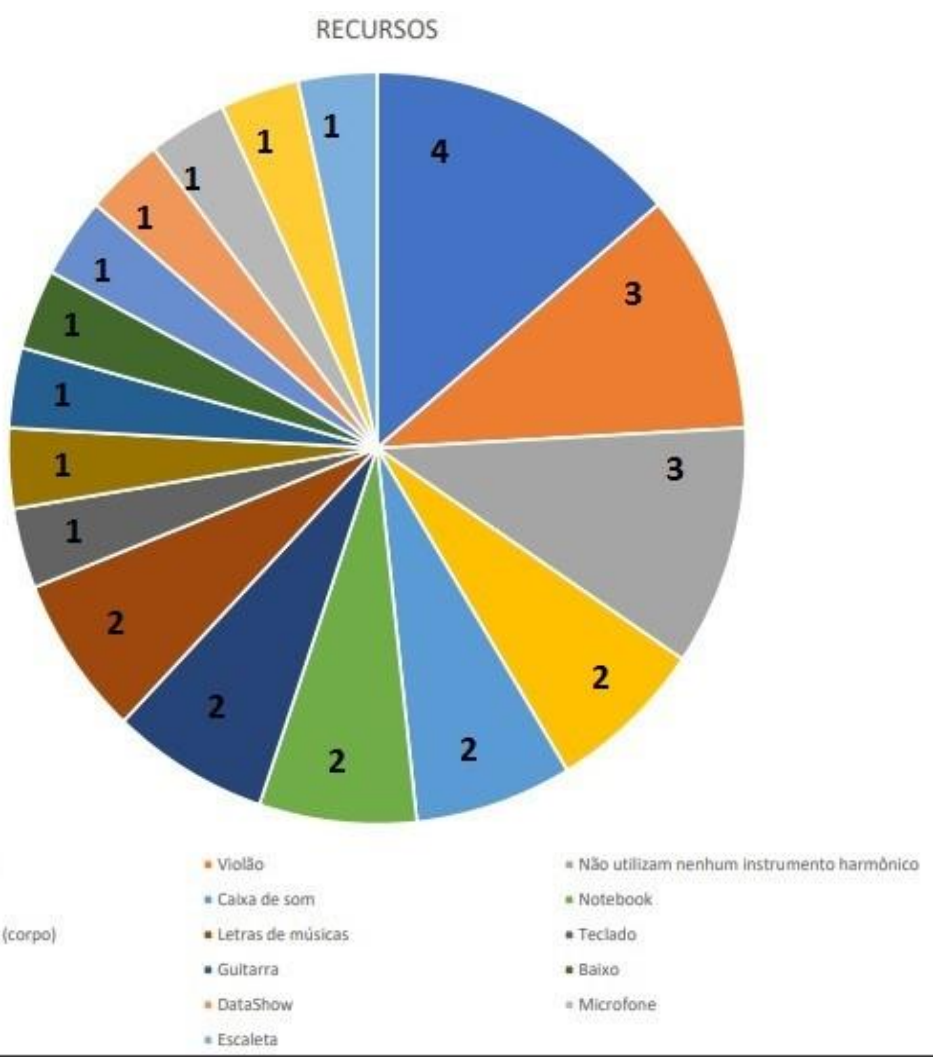

Figura 2: Recursos disponíveis para as aulas de canto

Uma infinidade de habilidades foram desenvolvidas junto aos bolsistas. Os ex-bolsistas tem consciência das habilidades necessárias para contemplar o canto coletivo, além disso, conduziram e desenvolveram atividades de maneira muito parecidas. Existem também outras maneiras interessantes de se abordar o canto coletivo e que poderiam atrair mais os estudantes. Braga (2010), Andrade (2014), Schmeling e Teixeira (2010) consideram que o canto coletivo pode contribuir para o desenvolvimento da afinação, da ampliação do repertório discente, da percepção e da consciência corporal, ao possibilitar perceber a música que está dentro de si, do conhecimento de si mesmo relacionados aos seus sons externos, (sons estes intrínsecos e particular), o que gera a manipulação discente da música ao seu redor. Os autores reforçam a importância de cantar na escola,

\footnotetext{
${ }^{4}$ Instrumentos harmônicos são aqueles que são possíveis tocar várias notas de uma única vez, razão pela qual são eficientes para o uso em acompanhamento vocal. Ex: o piano, o teclado, o violão, baixo, guitarra, a sanfona, o acordeão. (ALMEIDA, 2015, p.1)
} 
até como primeiro passo para o indivíduo ter um contato com o ensino da música de forma sistematizada.

\section{CONSIDERAÇÕES FINAIS}

Acredito que contribuiu para que outras pessoas que pesquisam ou atuam na área, possam desenvolver atividades com o canto coletivo na escola; contribuiu com a pesquisa do orientador, pois descreveu melhor uma atividade que pertence às práticas adotadas pelo PIBID de Música, onde minha orientadora foi coordenadora do Subprojeto, além de contribuir com a sistematização das práticas pedagógicas adotadas. Foi possível atingir os objetivos esperados, sendo estes de investigar como foram contempladas atividades que envolvem o canto coletivo, bem como verificar junto aos ex-bolsistas os desafios, o repertório utilizado, as habilidades, entre outros, sinalizando o que é necessário para se trabalhar com o canto coletivo na escola. Apesar do contexto ser o Subprojeto Musicando a Escola, vinculado ao PIBID de Música da UEFS, acredito que os dados coletados e analisados poderão ser adaptados e aplicados em outros contextos.

Pude refletir que a atividade do canto coletivo pode ser abordada e conduzida de diversas maneiras interessantes aos estudantes, inclusive com o auxílio de atividades complementares que desenvolvam habilidades importantes para se cantar, como a apreciação, um ouvir diferenciado que influenciará na afinação, ampliação de repertório que poderá auxiliar a conhecer diversas técnicas vocais, entre outros. Também foi importante reforçar a importância do canto coral para mim, pois ao longo da pesquisa pude notar os inúmeros benefícios que o canto proporciona ao indivíduo, tanto individual quanto no coletivo, oportunizando este a não se desvincular da música.

\section{REFERÊNCIAS}

ALMEIDA, Fernando. Instrumentos melódicos versus instrumentos harmônicos, 2015. Disponível em: < http://cifrasedicasdeteclado.blogspot.com/2015/05/instrumentosmelodicos-versus.html>. Acesso em: 13 ago 2018.

ANDRADE, Klesia Garcia. Canções e culturas: possibilidades educacionais por meio da voz. Música na Educação Básica. Londrina, v.6, n.6, 2014.

BRAGA, S. M. Canto coral no contexto escolar: definindo os conteúdos a serem desenvolvidos. Musifal: revista eletrônica de música da Universidade Federal de Alagoas, v. 02, p. 1-8, 2010.

FUCCI AMATO, R. DE C. O canto coral como prática sócio-cultural e educativomusica. Opus, Goiânia, v. 13, n. 1, p. 75-96, jun. 2007.

SCHIMITI, Lucy Maurício. 2003. Regendo um coro infantil... reflexões, diretrizes e atividades. Goiânia: Revista Canto Coral, Ano II, $N^{\circ} 1$.

SCHMELING, Agnes; TEIXEIRA, Lúcia. Explorando possibilidades vocais: da fala ao canto. Música na educação básica. Porto Alegre, v. 2, n. 2, setembro de 2010. 